\title{
UMA ANÁLISE DO PROCESSO DE CRIAÇÃO DA LEI MARIA DA PENHA NO CONTEXTO DE PROTEÇÃO AOS DIREITOS HUMANOS
}

\author{
Letícia Fonseca Paiva Delgado* \\ Renata Menezes de Jesus***
}

Resumo: Partindo da recomendação da Comissão Interamericana de Direitos Humanos quando da análise dos episódios de violência sofridos por Maria da Penha Maia Fernandes, o presente trabalho tem como objetivo explicitar o contexto de retomada da proteção aos direitos humanos que gerou a criação da Lei Maria da Penha. Para alcançar tal finalidade, buscaremos explicar não só como a esfera internacional influenciou na elaboração da referida lei, levando em conta principalmente a atuação do Sistema Interamericano de proteção aos direitos humanos, mas também os aspectos específicos internos que contribuíram para a criação desse instrumento normativo de proteção à mulher.

Palavras-chave: Lei Maria da Penha; Direitos Humanos; Sistema Interamericano; Violência Doméstica; Direito Internacional

\section{AN ANALYSIS OF THE CREATION PROCESS OF MARIA DA PENHA LAW IN THE CONTEXT OF HUMAN RIGHTS PROTECTION}

\begin{abstract}
Based on the recommendation of Inter-American Commission on Human Rights when analyzing the episodes of violence suffered by Maria da Penha Maia Fernandes, this paper aims to explain the context of the recovery of human rights protection that led to the creation of the Maria da Penha Law. To achieve this purpose, we will explain not only how the international sphere influenced the elaboration of this law, considering, in particular, the work of the Inter-American System for the protection of human rights, but also the specific internal aspects that contributed to the creation of this normative instrument of protection.
\end{abstract}

Keywords: Maria da Penha Law; Human Rights; Inter-American System; Domestic Violence; Internacional Rights.

\footnotetext{
* Graduada em Direito. Mestra em Ciências Sociais pela UFJF. Doutoranda em Sociologia e Direito pela UFF. Professora de Processo Penal na instituição Doctum e na PUC/MG. Advogada.

** Graduada em Direito pela Universidade Federal de Juiz de Fora - MG e Mestre em Ciências Jurídicointernacionais pela Faculdade de Direito da Universidade de Lisboa - Portugal. Professora de Direito Internacional e integrante da comissão de organização dos processos de internacionalização do Curso de Direito do Centro Universitário Estácio Juiz de Fora - MG. Coordenadora do Curso de Direito do Centro Universitário Estácio Juiz de Fora - MG. Advogada.
} 


\section{INTRODUÇÃO}

Em 04 de abril de 2001, a Comissão Interamericana de Direitos Humanos, no Relatório $\mathrm{n}^{\circ}$ 54/01, referente ao Caso 12.051 - Maria da Penha Maia Fernandes x Brasil, concluiu (item 60.2) que,

A República Federativa do Brasil é responsável da violação dos direitos às garantias judiciais e à proteção judicial, assegurados pelos artigos 8 e 25 da Convenção Americana em concordância com a obrigação geral de respeitar e garantir os direitos, prevista no artigo 1(1) do referido instrumento pela dilação injustificada e tramitação negligente deste caso de violência doméstica no Brasil.

Em virtude dessa conclusão, foram feitas ao Brasil, por esse órgão, recomendações não somente em relação ao caso Maria da Penha especificamente, mas também no sentido de o Estado brasileiro "prosseguir e intensificar o processo de reforma que evite a tolerância estatal e o tratamento discriminatório com respeito à violência doméstica contra mulheres" em todo o país. (item 61.4).

Importante destacar que a mencionada recomendação se insere num contexto de internacionalização e consolidação da tutela dos direitos humanos, com a criação de sistemas internacionais de proteção a tais direitos, como o Sistema Interamericano.

Em que pese à Lei Maria da Penha só ter sido promulgada em 07 de agosto de 2006, mais de 04 (quatro) anos após a referida recomendação da Comissão, é inquestionável que o movimento internacional de proteção às mulheres vítimas de violência doméstica e familiar começou antes, amparado pela Convenção sobre a Eliminação de Todas as Formas de Discriminação contra a Mulher e pela Convenção Interamericana para Prevenir, Punir e Erradicar a Violência contra a Mulher.

Não bastasse a influência internacional, mister se faz destacar que a Lei 11.340 de 2006 também foi fruto de vários discursos e insatisfações, no âmbito interno: o descontentamento do movimento feminista com a atuação do Poder Judiciário na administração desse tipo de conflito, notadamente em virtude da aplicação do procedimento previsto na lei 9.099/95 e de seus benefícios despenalizadores.

Nesse sentido, esse artigo tem como objetivo principal explicitar os contextos internacional e nacional que antecederam e permitiram a promulgação da denominada Lei Maria da Penha. A fim de alcançar tal finalidade, buscaremos abordar, inicialmente, como se estruturam e atuam os sistemas internacionais de proteção aos direitos humanos, com ênfase no Sistema Interamericano. Tal análise será importante para a compreensão, dentro de um 
contexto de internacionalização da tutela dos direitos humanos, do quadro geral em que a legislação pátria de insere e do que ela significou para a realidade jurídica brasileira. $\mathrm{Na}$ segunda parte do trabalho, serão apontados aspectos específicos que permitiram à mobilização interna em prol da criação de uma lei de combate à violência doméstica e familiar contra a mulher.

\section{O SISTEMA DE PROTEÇÃO AOS DIREITOS HUMANOS: O EMBRIÃO DA LEI MARIA DA PENHA}

\subsection{O SISTEMA UNIVERSAL DE PROTEÇÃO}

Partindo do objetivo principal deste artigo, qual seja explicitar os contextos internacional e nacional que antecederam e permitiram a promulgação, em 2006, da denominada Lei Maria da Penha, buscaremos abordar, inicialmente, como se estruturam e atuam os sistemas internacionais de proteção aos direitos humanos, com ênfase, principalmente, no Sistema Interamericano. Tal análise será importante até para comprovar a interferência internacional nas ordens internas, especialmente no que tange à proteção dos direitos humanos.

O Sistema Interamericano de proteção aos direitos humanos decorre diretamente da retomada da preocupação com a proteção dos direitos humanos após a segunda grande guerra mundial. O período do segundo conflito mundial, em grande medida pelos regimes nazista e fascista, foi certamente um dos períodos mais agressivos e violentos aos direitos dos indivíduos.

A despeito de haver quem defenda que os precursores da internacionalização dos direitos humanos na época contemporânea sejam as normas de direito humanitário e a criação da Liga das Nações e da Organização Internacional do Trabalho (OIT) (PIOVESAN, 2012, p. 175), não se pode negar que o Direito Internacional dos Direitos Humanos se consolidou efetivamente apenas na segunda metade do século passado, em decorrência direta da necessidade de uma intervenção da sociedade internacional na esfera protetiva dos direitos das pessoas humanas. Não se discute mais que a preocupação principal da sociedade internacional, após 1945, passa a ser a da reconstrução dos direitos humanos. Não apenas uma reconstrução exclusivamente internacional ou exclusivamente interna, mas foi preciso 
mais: foi necessário, sobretudo, que a redefinição dessa proteção se desse nos ordenamentos internacional e internos ao mesmo tempo.

A segunda metade do século XX passa, assim, a ser um marco significativo no Direito de uma maneira geral: a retomada da proteção aos direitos humanos no cenário internacional permite uma considerável intervenção do Direito Internacional nas ordens internas e, sem dúvida, isso promove um redesenho do conceito de soberania. Some-se a isso o surgimento de organizações internacionais com finalidade de fomentar a cooperação internacional, como a Organização das Nações Unidas (ONU), fundada em São Francisco, em 1945, tendo como objetivos principais a manutenção da paz e a proteção aos direitos humanos.

A Carta da ONU é a comprovação expressa da união de vontades de muitos Estados para fins de proteção da dignidade humana. Neste sentido:

(...) é a Carta de São Francisco, sem dúvida o primeiro tratado de alcance universal que reconhece os direitos fundamentais de todos os seres humanos, impondo o dever dos Estados de assegurar a dignidade e o valor do ser humano. Pela primeira vez, o Estado era obrigado a garantir direitos básicos a todos sob sua jurisdição, quer nacional ou estrangeiro. (RAMOS, 2012, p.51)

A importância do surgimento da ONU e da sua atuação na proteção dos direitos humanos é inquestionável. Não é menos verdade, no entanto, que a Carta das ONU adotou uma linguagem imprecisa e muito vaga no que tange a estes direitos. Desta forma, para esclarecer e definir o significado dos direitos humanos, se inicia um movimento de elaboração de tratativas e normas jurídicas internacionais capazes de auxiliar nessa definição e na identificação de tais direitos. Neste contexto, a Declaração Universal dos Direitos Humanos, de 1948, adotada pela resolução 217-A da Assembleia Geral da ONU, e os Pactos de Nova York de 1966 (Pacto Internacional de Direitos Civis e Políticos e Pacto Internacional de Direitos Econômicos, Sociais e Culturais), citados como os principais documentos internacionais de proteção aos direitos humanos, e que passam a integrar a chamada Carta Internacional dos Direitos Humanos. (PIOVESAN, 2012, p. 198 e ss.).

De lá para cá, a elaboração de documentos internacionais nesses moldes protetivos se intensificou, alguns com propostas mais generalizadas, outros com temas de proteção relacionados a categorias de pessoas determinadas, como, por exemplo, a Convenção para Eliminação de todas as Formas de Discriminação contra a Mulher.

Paralelamente a esse sistema universal de proteção aos direitos humanos, desenvolvido e mantido em grande medida pela ONU, surgem outros sistemas protetivos 
regionais: o sistema europeu de proteção aos direitos humanos, o sistema americano de proteção aos direitos humanos e o sistema africano de proteção aos direitos humanos.

A proposta aqui, em virtude do objeto principal do presente artigo, é aprofundar o estudo do sistema regional americano de proteção aos direitos humanos e a estrutura elaborada para manutenção desse sistema.

\subsection{O SISTEMA INTERAMERICANO DE PROTEÇÃO AOS DIREITOS HUMANOS}

O Sistema Interamericano de proteção aos direitos humanos tem como normativa principal a Convenção Americana de Direitos Humanos, também conhecida como Pacto de São José da Costa Rica. Tal convenção, assinada no âmbito da Organização dos Estados Americanos (OEA), é um tratado internacional que foi assinado em 1969, na Costa Rica, e que entrou em vigor em 1978. A OEA, por sua vez, é uma organização internacional criada pela Carta da OEA, tratado assinado em Bogotá, na Colômbia, em 1948, tendo entrado em vigor em 1951. Somente os Estados signatários da Carta da OEA têm a possibilidade de aderirem à Convenção Americana de Direitos Humanos.

O Brasil, Estado-membro da OEA e signatário da Convenção Americana de Direitos Humanos, depositou a sua ratificação ao Pacto de São José em setembro de 1992 e, em novembro do mesmo ano, foi promulgado, no Brasil, o Decreto Executivo n. 678, pelo então Presidente Itamar Franco, que reconhecia em âmbito local os termos da Convenção. Ao ratificar um tratado internacional, um Estado confirma a sua adesão aos termos daquela tratativa e às suas disposições passa a se subordinar. Assim, ao ratificar o Pacto de São José da Costa Rica, o Brasil, passa a se submeter às disposições da Convenção e às suas exigências.

A Convenção fortaleceu o sistema de direitos humanos implantado com a Carta da OEA e aclarado com a Declaração Americana de Direitos e Deveres do Homem (1948) (MAZZUOLI, 2016, p. 975). De antemão, prevê um elenco de direitos civis e políticos, similar ao rol previsto no Pacto Internacional de Direitos Civis e Políticos, de 1966. Não se refere, entretanto, originariamente e de forma específica, a nenhum direito econômico, social ou cultural, os também chamados direitos humanos de segunda geração, apesar de determinar que os Estados membros devam buscar alcançar a realização destes direitos progressivamente, inclusive com a adoção de medidas legislativas internas, conforme comprova a literalidade dos primeiros artigos da Convenção: 
Artigo 1. Obrigação de respeitar os direitos

1.Os Estados Partes nesta Convenção comprometem-se a respeitar os direitos e liberdades nela reconhecidos e a garantir seu livre e pleno exercício a toda pessoa que esteja sujeita à sua jurisdição, sem discriminação alguma por motivo de raça, cor, sexo, idioma, religião, opiniões políticas ou de qualquer outra natureza, origem nacional ou social, posição econômica, nascimento ou qualquer outra condição social.

2.Para os efeitos desta Convenção, pessoa é todo ser humano.

Artigo 2. Dever de adotar disposições de direito interno

Se o exercício dos direitos e liberdades mencionados no artigo 1 ainda não estiver garantido por disposições legislativas ou de outra natureza, os Estados Partes comprometem-se a adotar, de acordo com as suas normas constitucionais e com as disposições desta Convenção, as medidas legislativas ou de outra natureza que forem necessárias para tornar efetivos tais direitos e liberdades" (grifo nosso).

O preâmbulo da mencionada Convenção já afirma que somente se pode pensar o ser humano livre, "isento do temor e da miséria, se forem criadas condições que permitam a cada pessoa gozar dos seus direitos econômicos, sociais e culturais, bem como dos seus direitos civis e políticos (...)".

Tais direitos econômicos, sociais e culturais somente passaram a integrar o texto da Convenção expressamente alguns anos depois, já em 1988, quando a Assembleia Geral da OEA adotou o Protocolo de San Salvador. A partir deste Protocolo, todo Estado-parte assume a obrigação não apenas de respeitar esses direitos, mas também de assegurar cada um deles.

O Pacto também estabelece um aparato para o monitoramento e responsabilização para casos de violação aos direitos previstos no tratado, com dois órgãos, a Comissão Interamericana de Direitos Humanos (sede em Washington, EUA) e a Corte Interamericana de Direitos Humanos (sede em São José, Costa Rica), fortalecendo, assim, o sistema internacional de proteção aos direitos humanos.

\subsubsection{A Comissão Interamericana de Direitos Humanos}

A Comissão Interamericana é ao mesmo tempo órgão da OEA e da Convenção Americana de Direitos Humanos. Composta por sete membros eleitos pela Assembleia Geral da OEA dentre indivíduos da mais alta autoridade moral e de reconhecido saber em matéria de direitos humanos, para um mandato de 04 (quatro) anos, com uma reeleição possível.

Dentre as principais funções da Comissão, nos termos do art. 41, b, do Pacto, estão a de "formular recomendações aos governos dos Estados membros, quando o considerar conveniente, no sentido de que adotem medidas progressivas em prol dos direitos humanos no 
âmbito de suas leis internas e seus preceitos constitucionais, bem como disposições apropriadas para promover o devido respeito a esses direitos".

O processo perante a Comissão é regulado nos arts. 48 a 51 da Convenção e se inicia com uma denúncia, em forma de petição, apresentada por indivíduo, grupos de indivíduos ou entidades não governamentais (art. 44, CADH). A petição direcionada à Comissão deverá obedecer a requisitos e exigências previstos no próprio Pacto (art. 46, CADH), dentre eles o esgotamento das vias internas, salvo nos casos de demora processual injustificada, e a ausência de litispendência internacional. Segundo Mazzuoli, (2016, p.975-976),

\begin{abstract}
Não cabe a qualquer sistema internacional de proteção substituir a jurisdição estatal interna para fixar, v.g., as modalidades específicas de investigação e julgamento em um caso concreto. Cabe, em suma, ao Estado a responsabilidade imediata de proteção e ao sistema interamericano a responsabilidade protetiva mediata (tanto isso é verdade que um dos requisitos de admissibilidade de petições perante a Comissão Interamericana é o do prévio esgotamento dos recursos internos).
\end{abstract}

No caso de a Comissão reconhecer a admissibilidade da denúncia, requererá informações ao governo denunciado. Recebidas as informações, ou transcorrido o prazo sem que as tenha prestado o governo denunciado, a Comissão verifica se os motivos da petição subsistem. Se não mais existem os motivos da petição, a Comissão manda arquivar o expediente. Caso ainda subsistam, a Comissão fará uma apuração do assunto exposto na petição ou comunicação, com o conhecimento das partes. Nesse momento, a petição já é registrada como um “caso”. Em seguida, a Comissão deve se colocar à disposição das partes interessadas a fim de buscar uma solução amistosa. Caso a conciliação seja alcançada, a Comissão vai elaborar um relatório, a ser transmitido à Secretaria Geral da OEA para ser publicado. Não obtida à conciliação, a Comissão fará um relatório, reunindo fatos e conclusões e poderá apresentar proposições e recomendações ao Estado-parte denunciado (primeiro informe). O relatório dá ao Estado parte o prazo de três meses para cumprir as recomendações, nos termos do art. 51 da $\mathrm{CADH}$.

A Comissão fará as recomendações pertinentes e fixará um prazo dentro do qual o Estado deve tomar as medidas que lhe competirem para remediar a situação examinada. Transcorrido o prazo fixado, a Comissão decidirá, pelo voto da maioria absoluta dos seus membros, se o Estado tomou ou não medidas adequadas e se publica ou não seu relatório. (MAZZUOLI, 2016, p. 982).

Importante destacar que a Comissão não tem função de julgamento, mas apenas função consultiva, com emissão de pareceres. 
Foi exatamente esse o procedimento no caso que ficou conhecido como "Caso Maria da Penha": a impunidade e a inefetividade do sistema judicial brasileiro diante da violência contra esta mulher levaram o Centro pela Justiça e pelo Direito Internacional (CEJIL) e o Comitê Latino-Americano de Defesa dos Direitos da Mulher (CLADEM), em 1998, a apresentarem petição perante a Comissão Interamericana de Direitos Humanos.

Pouco mais de três anos depois, a Comissão, alegando negligência e omissão em relação à violência doméstica, recomendou que o Brasil concluísse efetivamente o processo penal contra o agressor e que investigasse as irregularidades e a demora injustificada na punição do marido, que promovesse a capacitação de funcionários da justiça em direitos humanos, que promovesse uma mudança legislativa e promovesse políticas públicas que coibissem os casos de violência doméstica e violência familiar e que pagasse uma indenização simbólica e material à vítima. ${ }^{1}$

O caso Maria da Penha corresponde ao primeiro caso de violência doméstica tratado pelo Sistema Interamericano de proteção aos direitos humanos. A Carta da ONU (1945), a Declaração Universal dos Direitos Humanos (1948), a Convenção sobre Eliminação de todas as Formas de Discriminação contra a Mulher (1979) e a Convenção Interamericana para Punir, Prevenir e Erradicar a Violência contra a Mulher, também denominada de "Convenção de Belém do Pará" (1994) serviram de fundamento principal para as recomendações feitas aos Brasil pela Comissão. Apesar da recomendação datar de 2001, somente em 2006 o Brasil elaborou uma legislação específica para a proteção das mulheres vítimas da violência doméstica.

A despeito de dezessete países da América Latina terem normatizado essa proteção específica à mulher antes do Brasil, não se pode negar que a recomendação da Comissão Interamericana ao Brasil constitui uma conquista histórica na afirmação dos direitos humanos das mulheres. Segundo Piovesan (2017, p. 414), o auge da luta das mulheres pelos seus direitos foi com a recomendação da Comissão ao Brasil no Caso Maria da Penha.

Em que pese à importância da atuação da Comissão Interamericana de Direitos Humanos, notadamente em virtude da recomendação que influenciou na promulgação da Lei Maria da Penha, é importante ressaltar que a comissão não é o único órgão que estrutura o

\footnotetext{
${ }^{1}$ Vide item 61 do Relatório 54/01, caso 12.051 - Maria da Penha Maia Fernandes x Brasil, de 04 de abril de 2001, Comissão Interamericana de Direitos Humanos). Disponível em: https://cidh.oas.org/annualrep/2000port/12051.htm
} 
mecanismo de proteção interamericana aos direitos humanos. A tal estrutura deve-se somar também à Corte Interamericana de Direitos Humanos.

\subsubsection{A Corte Interamericana de Direitos Humanos}

A Corte também é composta por sete juízes, mas diferentemente da Comissão, a Corte tem competência consultiva e contenciosa. No plano consultivo, qualquer membro parte ou não da Convenção - pode solicitar o parecer da Corte. No plano contencioso, a competência da Corte para julgamento é limitada aos Estados partes da Convenção que reconhecem expressamente tal jurisdição. As decisões da Corte têm força vinculante e obrigatória e, caso na sentença seja definido valor indenizatório, essa vale como título executivo - depois de o país reconhecer a jurisdição da Corte.

Mister se faz aqui destacar que o Caso Maria da Penha não foi analisado pela Corte Interamericana de Direitos Humanos, tão menos houve uma condenação do Brasil nesse caso. A análise pela Corte não foi possível visto que, quando dos crimes sofridos pela vítima em 1983, o Brasil ainda não tinha reconhecido a jurisdição da Corte, fato que ocorreu somente em 1998. Some-se a isso o fato de Comissão somente poder fazer recomendações, nunca condenações, já que não exerce jurisdição contenciosa.

Embora não tenha havido formalmente uma condenação do Brasil pela Corte, é inquestionável que a litigância internacional promoveu avanços internos no regime de proteção aos direitos humanos de uma maneira geral, bem como aos direitos específicos das mulheres, consolidando o discurso do direito à não violência como algo elementar dentro de um Estado Democrático de Direito.

\section{O CASO MARIA DA PENHA E O PROCESSO DE CRIAÇÃO DA LEI 11.340/2006 NO CONTEXTO NACIONAL: DA PENA DE "CESTA BÁSICA" AO ENCARCERAMENTO DO AGRESSOR}

Como dito, a litigância internacional e o fortalecimento dos sistemas de tutela internacional dos direitos humanos, de forma específica do direito das mulheres, tangenciou fortemente o processo de criação da Lei Maria da Penha no Brasil, sendo, assim, indispensável contextualizar tal temática dentro da lógica do direito internacional.

Não só no Brasil, por óbvio, mas as legislações e práticas de diversos outros países também foram influenciadas pelo discurso internacional e humanitário contra violência de gênero. Neste sentido, é a pesquisa de Simião (2015) que pretendeu descrever como o projeto 
modernizador, fortemente pautado na noção de indivíduo e de igualdade entre homens e mulheres, influenciou na construção da ideia de violência doméstica na recém-criada nação do Timor Leste.

André Simião, em sua obra denominada "As donas da palavra: gênero, justiça e a invenção da violência doméstica em Timor-Leste”, relata como a visão dos representantes de organismos oficiais como a ONU e demais agentes internacionais contribuíram decisivamente para a institucionalização do discurso de gênero no Timor Leste. A pesquisa, que teve como campo o Timor Leste recém-saído de um traumático período de luta e transição pela sua independência em relação à Indonésia, foi desenvolvida com a finalidade inicial de estudar as práticas organizacionais internacionais que trabalhavam com o tema de gênero em Timor Leste, tendo como foco a etnografia dos processos, tensões e disputas de significado em torno da categoria de "violência doméstica", ou, na língua nativa, "violência domestika". (Simião, 2015, p.19/20).

No entanto, nosso objetivo, neste tópico, será explicitar a forma como esse processo ocorreu no Brasil, culminando na promulgação, em 07 de agosto de 2006, da lei 11.340, que, como expõe a sua ementa,

cria mecanismo para coibir a violência doméstica e familiar contra a mulher, nos
termos do $\$ 8^{\circ}$ do art. 228 da Constituição Federal, da Convenção sobre a Eliminação
de Todas as Formas de Discriminação contra a Mulher e da Convenção
Interamericana para Prevenir, Punir e Erradicar a Violência contra a Mulher, dispõe
sobre a criação dos Juizados de Violência Doméstica e Familiar contra a Mulher;
altera o Código de Processo Penal, o Código Penal e a Lei de Execução Penal; e dá
outras providências.

A Lei Maria de Penha, como ficou conhecida a lei 11.340/06, é uma lei de iniciativa do Poder Executivo, tendo sido encaminhada ao Congresso Nacional por iniciativa do expresidente da república Luiz Inácio Lula da Silva. O projeto de lei foi elaborado por um consórcio de entidades feministas, sendo que a menção à Maria da Penha, que se tornou símbolo da luta contra a violência contra a mulher, acaba por refletir uma das características das legislações gestadas em movimentos de caráter identitário: leis com nomes de vítimas. Garland (2005, p. 240-243), que apresenta uma visão crítica a essa prática, afirma

A atribuição do nome de um indivíduo a uma lei e uma forma de neutralizar as objeções que essa lei possa sofrer. Após o processo de santificação da vítima, geralmente uma mulher ou uma criança, de um crime violento, passa a existir uma invalidação das preocupações com o delinquente, pois este deve ser punido de forma rígida e exemplar, para que possa "pagar pelo que fez". Qualquer menção aos 
direitos do delinquente ou a humanização do seu castigo pode ser facilmente considerado como um insulto às vítimas e aos seus familiares.

A escolha do nome da lei foi feito pelo então presidente Lula que, quando da sanção, afirmou: "Esta mulher renasceu das cinzas para se transformar em um símbolo da luta contra a violência doméstica em nosso país" (DIAS, 2015, p.21).

Como dito, a lei foi batizada em homenagem à Maria da Penha Maia Fernandes, biofarmacêutica cearense, que por vinte anos lutou para ver seu marido agressor, o professor universitário Marco Antonio Heredia Viveros, preso. A vítima sofreu duas tentativas de homicídio por parte do marido. Em 1983, enquanto dormia, a ofendida levou um tiro nas costas, ficando paraplégica. A segunda tentativa de homicídio aconteceu meses depois, quando Viveros empurrou Maria da Penha da cadeira de rodas e tentou eletrocutá-la no chuveiro.

Após 15 anos de demora injustificada na prestação jurisdicional, com auxílio de algumas ONGs e impulsionada pela grande pressão exercida pela comunidade internacional, Maria da Penha conseguiu enviar o caso para a Comissão Interamericana de Direitos Humanos (OEA) que, pela primeira vez, acatou uma denúncia de violência doméstica. Viveros só foi preso em 2002, condenado a uma pena de dois anos de prisão. Em virtude da negligência e demora na prestação jurisdicional neste caso concreto, como já dito, a Comissão recomendou a criação de uma legislação adequada a esse tipo de violência.

Segundo Fortuna e Delgado (2014), foi o processo de internacionalização dos direitos humanos que influenciou a adoção de ações estatais positivas em busca da promoção de políticas públicas estatais para o alcance da igualdade material, visando eliminar a violência doméstica contra a mulher. A introdução de políticas de ações afirmativas buscou a observância destes fatores culturais de diferenciação entre gêneros. A Convenção Interamericana para prevenir, sancionar e erradicar a violência contra a mulher - Convenção de Belém do Pará, reconheceu a violência contra a mulher como um fenômeno generalizado, que transcende todos os setores da sociedade, afirmando, em seu preâmbulo, "que a violência contra a mulher constitui violação contra os direitos humanos e das liberdades fundamentais, é uma ofensa à dignidade humana e uma manifestação de relações de poder historicamente desiguais entre mulheres e homens".

Datada de 2006, a lei em comento encontrou espaço aberto e campo fértil no Brasil, notadamente por conta das muitas críticas ao procedimento previsto pela lei 9.099/95, que, ao instituir os juizados especiais criminais, determinou o procedimento sumaríssimo para 
processar e julgar as infrações penais de menor potencial ofensivo que englobam lesões corporais leves e ameaças, delitos que as mulheres mais denunciam. No que concerne à lei 9.099/95 e à atuação dos JECrim, eram comuns indicações que apontavam para a impunidade do agressor, principalmente por conta dos casos de arquivamento e prescrição, possibilidade de transação penal e outras medidas despenalizadoras, questões que geravam desconforto e insegurança para as vítimas.

Machado (2002), em conclusão sobre a pesquisa realizada sobre o funcionamento das Delegacias de Mulheres no Brasil, apontou para os principais desafios da violência conjugal para os Juizados Especiais Criminais, a partir do reconhecimento que a tarefa é difícil, "dado ao enraizamento de uma cultura que insiste em silenciar sobre a violência interpessoal contra a mulheres" (MACHADO, 2002, p.16). Segundo a autora, a experiência das delegacias de mulheres reforça o que os estudos sobre violência conjugal apontam: lesões corporais e ameaças são consentâneas. No entanto, segundo Machado (2002, p.16), "se 80\% dos casos atendidos pelos Juizados Especiais Criminais referem-se a lesões consideradas de menor impacto no contexto de relações conjugais ou amorosas, é preciso não se equivocar com a aparência de que se trata, por natureza, de evento único e isolado”.

Ao construir essa ideia, Machado apresenta três questões sobre os desafios enfrentados sobre a administração dos conflitos relativos à violência contra a mulher no ambiente doméstico e familiar: a primeira questão é a impropriedade de se entender que atos violentos, por serem passíveis de pequenas punições, são irrelevantes e de pequeno prejuízo para as vítimas.

A segunda questão está relacionada ao fato de que esse tipo de violência não representa um ato isolado e sim um processo violento, sendo que

\footnotetext{
Ao se pensar como estão sendo construídas as suas formas de agir pelos juizados especiais, há que se perguntar sobre como julgar, como mediar, e como conciliar os sujeitos, não em torno de um isolado ato já passado, mas em torno de um ato que provavelmente se dá num contexto de relacionamento onde convivem insidiosamente amor e violência Se o elemento desencadeador do processo judicial é apenas um único ato violento, os processos de mediação, transação e conciliação se dão entre sujeitos imergidos num processo violento. (MACHADO, 2002, p. 16).
}

Por fim, a última questão apresentada pela autora trata principalmente dos processos de conciliação e mediação propostos pela Lei 9.099/95. Nesse sentido, a desigualdade estrutural, cultural e histórica entre homens e mulheres colocam os parceiros em posições 
desiguais de poder, fato este que impede uma mediação em reais condições de igualdade entre pares.

Segundo Amaya (2015, p. 26), neste contexto de insatisfação com a lei 9.099/95 e compartilhando as críticas feministas, principalmente aquela relativa à "preocupação com o réu e não com a vítima", a Lei Maria da Penha representa, além da tradução da "insatisfação com o tratamento dispensado pelos JECrim", o investimento em uma nova aposta que se idealiza como "mais eficiente e justa", com foco na "reforma dos dispositivos jurídicos" e na “judicialização da intimidade como via privilegiada para garantir os direitos das mulheres e promover justiça de gênero". Montenegro (2015, p. 103), ao se referir à aplicação da Lei 9.099/95, afirma:

\footnotetext{
Para grande parte dos discursos feministas, essa lei teria banalizado a violência doméstica e contribuído para: o arquivamento massivo dos processos, reprivatização do conflito doméstico e a redistribuição do poder ao homem mantendo-se a hierarquia de gênero.
}

Percebe-se que há uma convergência de fatores para a edição da Lei Maria da Penha. Por um lado, o Brasil estava sob os efeitos de uma recomendação da Comissão Interamericana de Direitos Humanos, motivada pelo reconhecimento internacional da negligência estatal com o combate e enfrentamento à violência doméstica e familiar contra a mulher. A pouca gravidade simbólica, moral e jurídica dada a estes casos internamente foi publicizada internacionalmente.

No entanto, o ativismo jurídico internacional foi combinado com a mobilização sistemática nas instituições políticas nacionais e na sociedade, conforme descrito por Maciel (2011). Isso significa que a mobilização interna também evidenciou contornos que demonstravam a insatisfação com a administração desses tipos de conflitos pelos Juizados Especiais Criminais. Assim, uma das demandas apresentadas pelo consórcio de organizações feministas criado para a elaboração de um projeto de lei focado no tratamento jurídico da violência doméstica contra a mulher era a elaboração de uma lei integral de enfrentamento à violência doméstica e familiar contra as mulheres, com o afastamento completo da lei 9.099/05 para os casos de violência conjugal.

A lei 11.340 de 2006 surge dando voz a várias demandas do movimento feminista, mas, principalmente, gera o afastamento da competência dos juizados especiais criminais, e seus típicos instrumentos conciliatórios e despenalizadores, como a composição civil dos danos, a transação penal e a suspensão condicional do processo, conforme previsto no art. 41 da Lei 11.340/06, que dispõe: "aos crimes praticados com violência doméstica e familiar 
contra a mulher, independentemente da pena prevista, não se aplica a lei $n^{\circ} 9.099$, de 26 de setembro de 1995". Como alternativa, a lei determinou a criação dos juizados de violência doméstica e familiar contra a mulher, nos termos do art. 14 da mencionada lei.

\begin{abstract}
Revelou-se o Judiciário como hermético e refratário às reivindicações das mulheres, reprodutor em suas práticas de arquétipos que reforçam a desigualdade de gênero e a discriminação contra as mulheres. Segundo a descrição de Lavigne (2009), creditava-se a atuação insatisfatória do poder Judiciário à fragilidade do ordenamento jurídico a partir do tratamento legislativo dispensado ao fenômeno, que acabava por fazer com que o Judiciário ratificasse os papéis de gênero e a hierarquia social em suas decisões, especialmente quando os delitos decorrentes desses conflitos passaram a ser tratados como de menor potencial ofensivo, conduzidos pela lei 9.099/95. Ao passo que no cenário internacional a violência contra a mulher consolidava-se em conferências, documentos e convenções como violação de direitos humanos. (AMAYA, 2015, s/p).
\end{abstract}

Além da impossibilidade da aplicação dos benefícios da lei 9.099/95 e da possibilidade de aplicação de medidas protetivas de urgência, a Lei Maria da Penha incrementou a sanção do tipo penal de lesão corporal simples, ao criar a forma qualificada do delito prevista no art. $129, \S 9^{\circ}$ do Código Penal:

Art. $129, \S 9^{\circ}, \mathrm{CP}:$ Se a lesão for praticada contra ascendente, descendente, irmão, cônjuge ou companheiro, ou com que conviva ou tenha convivido, ou ainda, prevalecendo-se o agente das relações domésticas, de coabitação ou de hospitalidade: (Redação dada pela Lei 11.340, de 2006).

Pena: detenção, de 3 (três) meses a 3 (três) anos. (Redação dada pela Lei no 11.340 , de 2006.

A Lei Maria da Penha representa a insatisfação coletiva do movimento feminista com o tratamento conferido pelos juizados especiais a tais delitos, bem como um investimento em um modelo de justiça mais eficiente, com a judicialização da vida privada e incremento da punição aos homens agressores. Segundo Montenegro (2015, p.103/104)

A crítica feita pelos grupos feministas à lei 9099/95 é contundente, e essa lei, como se depreende dos textos acima transcritos, teria trivializado a violência doméstica do homem contra a mulher, legitimando as ameaças, as injúrias e as surras. Essa minimização do Direito Penal, através das medidas despenalizadoras aplicadas às infrações penais de menor potencial ofensivo seria positiva apenas "na perspectiva do autor do fato e negativa na perspectiva da vítima de violência.

No que tange à punição, o sistema brasileiro de enfrentamento à violência doméstica e familiar contra a mulher passa por uma substancial alteração de paradigma: da pena de "cesta básica" ao encarceramento do agressor.

Apesar dos progressos e alterações substanciais no modelo de enfrentamento a violência contra a mulher pelas instituições, notadamente pelo Poder Judiciário, alguns 
desafios ainda são latentes, como a falta de articulação da rede de atendimento a este tipo de violência. Segundo a Comissão Parlamentar Mista de Inquérito (CPMI) da Violência contra a Mulher, em relatório de 20132: "Não encontramos integração e interação entre os diversos componentes da rede, além do estabelecimento de procedimentos próprios sem a devida discussão entre os integrantes da rede" (p.631).

Frise-se que a falta de superação de obstáculos como o acima mencionado podem reduzir a Lei Maria da Penha somente ao seu aspecto punitivo e encarcerador, relegando ao esquecimento seu real potencial.

\section{CONSIDERAÇÕES FINAIS}

Conforme se pode perceber, é perfeitamente possível concluir que a elaboração da Lei Maria da Penha se deu, em grande medida, na esteira do movimento mundial de retomada da proteção aos direitos humanos no pós segunda guerra. O surgimento do sistema universal de proteção aos direitos humanos e dos sistemas regionais de proteção paralelos foi, sem dúvidas, a mola propulsora da proteção específica dos direitos das mulheres vítimas de violência doméstica e violência familiar no Brasil e mesmo em outros Estados.

Ao se fazer referência aos sistemas internacionais regionais de proteção aos direitos dos indivíduos, o artigo pretendeu evidenciar especialmente o sistema americano de proteção, vez que a Lei 11.340/06 foi elaborada a partir de uma recomendação da Comissão Interamericana de Direitos Humanos, órgão com função apenas consultiva do referido sistema. Conforme ficou claro, o sistema americano protetivo não se estrutura em apenas um órgão, mas dele ainda faz parte a Corte Interamericana de Direitos Humanos, esta com função não só consultiva, mas principalmente contenciosa. E isso desfaz a confusão cometida por muitos ao anunciar que a elaboração da referida Lei Maria da Penha aconteceu por uma condenação da Corte Interamericana.

O estudo comprovou que o Brasil elaborou uma lei de proteção às mulheres vítimas da violência doméstica e familiar tardiamente, após muitos outros Estados terem tido essa iniciativa, e mais - que a atitude do Estado brasileiro na elaboração dessa lei deveu-se, em

\footnotetext{
${ }^{2}$ Disponível em: http://www.senado.gov.br/atividade/materia/getPDF.asp?t=133656\&;tp=1.
} 
muito, pela ingerência internacional atual nas ordens internas, principalmente no que tange à proteção de direitos humanos.

Restou esclarecido, ainda, que o Caso Maria da Penha Maia Fernandes x Brasil foi o primeiro caso de violência doméstica avaliado pelo sistema americano de proteção aos direitos humanos e que, a despeito da influência internacional na ordem jurídica brasileira, não se pode negar que, internamente, alguns movimentos sociais protetivos também preparam o terreno para a chegada e implantação da lei 11.340/06.

Dentre esses movimentos, imprescindível citar o movimento feminista contra o tratamento conferido pela Lei $9.099 / 95$ aos delitos praticados por homens agressores às mulheres e os movimentos em prol de um modelo de justiça mais justo e eficiente para as mesmas.

Das principais consequências da Lei Maria da Penha indica-se o afastamento da competência dos Juizados Especiais Criminais para julgar as agressões e crimes contra as mulheres, evitando, assim, que o Judiciário continuasse a ratificar a hierarquia social e a ideia de que delitos dessa natureza eram apenas delitos de menor potencial ofensivo.

Mais de doze anos após a criação da Lei Maria da Penha e a despeito de todas as conquistas que podem ser evidenciadas e toda a modificação no tratamento legal aos casos de violência doméstica e familiar contra as mulheres no Brasil, a verdade é que ainda existem muito obstáculos a serem superados. Mecanismos de integração e articulação da sociedade em prol de proteção e apoio são - e serão sempre - de fundamental importância para mulher e para a garantia de seus direitos.

\section{REFERÊNCIAS}

AMAYA, A. C. L. Fazer acontecer a Lei Maria da Penha no sistema de justiça? Um estudo empírico das práticas de significações de um juizado de violência doméstica e familiar contra a mulher no estado do Rio de Janeiro. 2015. Dissertação (Mestrado em Sociologia e Direito) Universidade Federal Fluminense. Niterói. 2015.

BRASIL, Lei ${ }^{\circ} 11343$, de 07 de agosto de 2006. Cria mecanismos para coibir a violência doméstica e familiar contra a mulher, nos termos do $\S 8^{\circ}$ do art. 226 da Constituição Federal, da Convenção sobre a Eliminação de Todas as Formas de Discriminação contra as Mulheres e da Convenção Interamericana para Prevenir, Punir e Erradicar a Violência contra a Mulher; dispõe sobre a criação dos Juizados de Violência Doméstica e Familiar contra a Mulher; altera o Código de Processo Penal, o Código Penal e a Lei de Execução Penal; e dá outras providências. Brasília, DF. Disponível em: http://www.planalto.gov.br/ccivil_03/_ato20042006/2006/lei/111340.htm 
Decreto-Lei 2848, de 07 de dezembro de 1940. Código Penal. Brasília, DF. Disponível em: http://www.planalto.gov.br/ccivil_03/decreto-lei/Del2848compilado.htm

DIAS, M. B. Lei Maria da Penha: a efetividade da lei 11.340/2006 de combate à violência doméstica e familiar contra a mulher. São Paulo: Revista dos Tribunais, 2015.

DELGADO, L. F. P; FORTUNA. L. M. R. O direito à intimidade da vítima de lesões corporais leves no âmbito da Lei Maria da Penha. In: JÚNIOR, A. P. G.; SANTOS, M. G. T (Orgs.) Reflexões sobre a Constituição Brasileira de 1988 em seu 25 aniversário. Curitiba: Juruá. $1^{\text {a }}$ Ed, 2014, p.203-214.

GARLAND, D. La cultura del control: crime y orden social en sociedade conteporánea. Tradução Máximo Sozzo. Barcelona: Gedisa, 2005.

GUERRA, S. Curso de Direito Internacional Público. São Paulo: Saraiva, 2016.

Machado, L. Z. Atender vítimas, criminalizar violências. Dilemas das Delegacias da Mulher. Série Antropologia. $\mathrm{n}^{\circ}$ 319. (Unb) Brasília. 2002. Disponível em: http://www.dan.unb.br/images/doc/Serie319empdf.pdf

MAZZUOLI, V. O. Curso de Direito Internacional Público. São Paulo: RT, 2016.

MONTENEGRO, M. Lei Maria da Penha: uma análise criminológica-crítica. Rio de Janeiro: Revan, 2015.

PIOVESAN, F. Temas de direitos humanos. São Paulo: Saraiva, 2017.

2012.

Direitos humanos e o Direito Constitucional internacional. São Paulo: Saraiva, Direitos humanos e justiça internacional. São Paulo: Saraiva, 2006.

RAMOS, A. C. Teoria geral dos direitos humanos na ordem internacional. São Paulo: Saraiva, 2012.

Relatório Anual 2000. Relatório n ${ }^{\circ}$ 54/01 do Caso 12.015, Maria da Penha Maia Fernandes, 2001. Comissão Interamericana de Direitos Humanos: Organização dos Estados Americanos. Disponível em: https://cidh.oas.org/annualrep/2000port/12051.htm

SIMIAO, D. S. As donas da palavra: gênero, justiça e a invenção da violência doméstica em Timor-Leste. Brasília: Universidade de Brasília, 2015. 